\title{
THE ANALYSIS OF PREPOSITIONAL PHRASE IN NOVEL 'THE PERFECT NANY' WRITTEN BY LEILA SLIMANI
}

\author{
Astri Thea Rahmanita \\ Ice Sariyati \\ Yuyun Nurulaen \\ State Islamic University of Sunan Gunung Djati Bandung
}

\begin{abstract}
Prepositional Phrase is the part of preposition and absolutely it is the part of grammar too. It has rules and deregulations that must be obeyed. Without a correct replacement of preposition, the meaning of the sentence can make the people confused. Hence, the research questions of this research are: 1) What are the positions of prepositions phrase of sentences found in Novel The Perfect Nany written by Leila Slimani?. 2) What are the patterns of tree diagram for a prepositional phrase of sentences found in Novel The Perfect Nany written by Leila Slimani?. The researcher use Position of Prepositional Phrase theory by Frank (1972) and theory of a tree diagram by Delahunty and Garvey (2010) to analyze the data. The findings show that the position of prepositional phrase in novel The Perfect Nany written by Leila Slimani is dominated by position in adverbial function (34 data). And the position in adjectival function is only found with 16 data. Base on the data analysis, it can be concluded that prepositional phrase adverbial function is more widely used than prepositional phrase adjectival function, because it can modify the verb, adverb, and adjectival that are mostly found in sentences. It is was also concluded that in one sentence there could be more than one prepositional phrase through the tree diagram that have been analyzed.
\end{abstract}

Key words: Prepositional Phrase, Adverbial Function, Adjectival Function

\section{Introduction}

Word is what is utterenced by someone in speaking/communicating. Word is defined as some experts quite same. Words is a minimal free form, the term word is used to designate an intermediate structure smaller than a whole phrase and yet generally larger than a single sound segment. The simple manner to know what the meaning of word is usually it is listed in dictionaries, and may be separated in speech by pauses. Words consist of one or more morphemes and which typically occurs in the structure of phrases (Jackson,2000:48).

According to Jackson, et al (2000:50) there are four characteristics considered essentially in definition of the word in English, these are:

First, the word is an uninteruptible unit. When elements are added to a word to modify its meaning, they are never included within that word. They respect the internal stability of the word are added either as the beginning as prefixes of the word or at the end as suffixes.

For example: The prefix un-added to the words aware $\longrightarrow$ unaware

The suffix -able added to the words drink $\longrightarrow$ drinkable 
Secondly, the word may consist of one or more morphemes. When it consists of one morpheme only, then it cannot be broken down into smaller meaningful units. Example: dog, hand, man, out, work. These are called "simple" words, which are typically „minimum free forms, in sense that they may stand by themselves. When words consist of more than one morpheme, they may be either complex or compund.

- Complex words may be broken down into one free form and one or more bound forms. Example: dog-s, happi-ly, quick-er, work-ing

- Compound words consist of more than one free form. Example: birthday, black-bird, candle-stick, coat-hanger.

Thirdly, the word occurs typically in the structure of phrases. Then morphemes are used to build words, words to build phrases, phrases to build clauses, and clauses to build sentences.

Finally, it is also an important characteristic of each word that it should belong to a specific word class or part of speech. According to Quirk et al. (1985:67) distinguish word as follow:

- Closed classes: preposition, pronoun, determiner, conjunction, auxiliary verb.

- Open classes: noun, adjective, verb, adverb.

- Lesser categories: numeral, interjection

- A small number of words of unique function: the particle not and the infinitive marker to.

According to Quirk et al. (1985) state that the closed classes is called "grammatical" or "function" words, which generally serve the grammatical construction of sentences. They are small classes, with a restricted and largely unchanging membership. The open classes, by contrast, are larger, and they are constantly being added to. The member of the open classes are the "content" words, carrying the main meaning of a sentence, they are the words likely to be retained in a telegram or a headline. It is not generally possible to tell which word class a belongs to, simply by looking at it, though inflections may provide a clue”. Example:

A word ending in -ing is likely to be a verb,

And one ending in - est an adjective

However, to be sure it needs to study about a word behavior in sentences. All words that function in the same way are deemed to belong to the same word class. For example, consider the following sentence:

on

The book was in the cupboard

\section{Under}

Since they behave the same way in the sentence, they belong to the same word class, which is called "preposition". The nation of word class is therefore useful 
because it allows us to make general and economical statements about the way the words of a language behave.

Phrases are groups of word contains with determiner, pre-modifier, head, post-modifier they do not contain subject and predicate. As like Richard, et al. (1985:39) say that "a phrase is a group of word which forms a grammatical unit, a phrase does not contain a finite verb and does not have a subject-predicate structure".

Gelderen, (2002:43) assumes that a phrase is a group of words forming a unit and united around a head, ex: a noun or a verb. Since phrases are syntactic units, a number of rules apply to them. Beside that I find some definitions about phrase from different sources. Some of them are :

Dalahunty and Garvey (2000:274) state that "Traditional phrase is defined as a group of words that does not contain a verb and its subject and is used as a single part of speech."'This definition entails three characteristics: (1) it specifies that only a group of words can constitute a phrase, implying that a single word cannot; (2) it distinguishes phrases from clauses; and (3) it requires that the groups of words believed to be a phrase constitute a single grammatical unit".

Verspoor, and Sauter (2000:118) in their books of English Sentence Analysis. An Introductory Course. State that "a phrase can consist of one word or more words. If it consists of more words, it usually has one main word that is the most important one as far as meaning is concerned".

A phrase is two or more words that do not contain the subject-verb pair necessary to form a clause. Phrases can be very short or quite long. Certain phrases have specific names based on the type of word that begins or governs the word group. There are eight types of phrases, they are: noun phrase, verb phrase, adjective phrase, adverbial phrase, prepositional phrase, infinitive phrase, gerundive phrase, and participle phrase (Prastowo,2009).

Prepositional Phrase is a combination of two elements 'preposition' and 'phrase'. Each element has its own definition. Preposition are always followed by nouns or pronouns. Prepositions are connective words that show the relationship between the nouns following them and one of the basic sentences elements: subject, verb, object, or complement (Wishon \& Burks:1980).

The Position of prepositional phrase are divided into two types of position, in Adjectival Function and in Adverbial Function (Frank, 1972). In Adjectival function, adjective prepositional phrases follow the nouns they modify, unlike adjectives which generally go immediately before the nouns they modify. Like adjectives, they tell which one, what kind, how much, or how many.

Here are some examples:

The show Ion television tonight is about snow leopards lin Asia.

On television tells us which show. In Asia tells us which leopards. In Adjectival function, one or more prepositional phrases may follow the noun head, with no commas between them These prepositional phrases.

Adverb prepositional phrases that modify adjectives and verbs must go after the words they modify. Like intensifiers, they tell to what extent. They can also tell why or in what way or in what circumstances. 


\section{Finding and Discussion}

There are 50 data of prepositional phrases that used in the novel The Perfect Nany written by Leila Slimani. Based on Frank (1972) the Position of prepositional phrase are divided into two types of position, in Adjectival Function and in Adverbial Function there. The following present the results of the data analysis based on the most data found.

\section{Position of Prepositional Phrase}

Prepositional Phrase is a combination of two elements 'preposition' and 'phrase'. Each element has its own definition. Preposition are always followed by nouns or pronouns. Prepositions are connective words that show the relationship between the nouns following them and one of the basic sentences elements: subject, verb, object, or complement (Wishon \& Burks:1980).

Data no 1:

At this hour, you are ashamed of your uselessness.

Based on the data above, "of your uselessness" this prepositional phrase constructed by the preposition "of" and "your uselessness" as an object of preposition. As According Frank's theory, in position of prepositional phrase in adverbial function, prepositional phrases that modify adjectives and adverbs must go after the words they modify. The prepositional phrase in the sentence above is modify a word "ashamed", which is an adjective. Prepositional phrase "of your uselessness" is adverbial function. "of your uselessness" is set off by comma in the end of the sentence. So, the position of the prepositional phrase in the sentence is adverbial function final position.

Data no 2:

The broken body, surrounded by toys, was put inside a grey bag, which they zipped shut.

Based on the data above, "inside a grey bag" is prepositional phrase in the position of adverbial function. "inside" as preposition and a grey bag as an object of preposition, connected with the word "put", "put" is a verb. Prepositional phrase "Inside a grey bag" is adverbial function. "inside a grey bag" is set off by comma in the middle of the sentence. The position of the prepositional phrase in the sentence is adverbial function mid-position.

Data no 3:

The toys were put in transparent bags and sealed as evidence.

Prepositional phrase in the sentence above is "in tranparent bags". "in" as preposition and "transparent bags" as object of preposition. "In transparent bags" is prepositional phrase in the position of adverbial function because the prepositional phrase connected with the verb "put". Prepositional phrase "in transparent bags" is adverbial function. 


\section{Data no 4:}

When she went into the room where the children lay, she let out a scream, a scream from deep within, the howl of a she-wolf.

In the sentence above "into" is the preposition and it is followed by the noun "the room", which is the object of preposition in the sentence. The prepositional phrase into the room modify the word "went", and "went" is a verb. The position of prepositional phrase into the room is an adverbial position. "into the room" is set off by comma in the sentence opening. The position of the prepositional phrase in the sentence is adverbial function initial-position.

\section{Data no 5:}

They stand on tiptoe, trying to make out what is happening behind the police cordon, inside the ambulance as it sets off, sirens screaming.

One of prepositional phrase in the sentence above is "behind the police cordon", this prepositional phrase in the position of adverbial function. Because "behind" as preposition and "the police cordon" as an object of preposition is connected with the word "happening", and the "happening" is a verb. The prepositional phrase "behind the police cordon" is set off by comma in the middle of the sentence. So, the position of the prepositional phrase in the sentence is an adverbial function midposition.

Data no 6:

They stand on tiptoe, trying to make out what is happening behind the police cordon, inside the ambulance as it sets off, sirens screaming.

Another preposition phrase in the sentence above is "inside the ambulance". "inside" as preposition and "the ambulance" as an object of preposition. The prepositional phrase in the position of adverbial function. This prepositional phrase related to "happening", happening is a verb. And the prepositional phrase "inside the ambulance" is set off by comma in the middle of the sentence. So, the position of the prepositional phrase in the sentence is adverbial function mid-position.

Data no 7:

Something terrible has happened to the children.

In the sentence above the prepositional phrase is "to the children". "to" as preposition and it is followed by the noun "the children", which is the object of preposition in the sentence. The prepositional phrase "to the children" modify the word "happened", and it is a verb. The position of prepositional phrase to the children is adverbial position.

Data no 8:

It's the smallest apartment in the building.

Based on the data above, "in the building" this prepositional phrase constructed by the preposition "in" and "the building" as an object of preposition. The prepositional phrase found in the sentence above is related to a noun "Apartment". 
As According Frank's theory, in position of prepositional phrase in adjectival function, prepositional phrases follow the nouns they modify. This prepositional phrase modify noun, functions as an adjective phrase.

Data no 9:

Paul and Myriam built a dividing wall in the living room when their second child was born.

The prepositional phrase in the sentence above is "in the living room", the object of preposition "the living room" related to the word before "wall", wall is a noun, the preposition in connects the living room with the noun wall. The function of this prepositional phrase is as an adjective.

Data no 10:

Myriam likes Berber rugs and furniture that she finds in antique stores.

Based on the data above, "in antique store" this prepositional phrase constructed by the preposition "in" and "antique store" as an object of preposition. As According Frank's theory, in position of prepositional phrase in adjectival function, prepositional phrases follow the nouns they modify. The prepositional phrase found in the sentence above is modify the noun "furniture", this prepositional phrase modifies noun functions as an adjective phrase.

Data no 11:

She has hung Japanese prints on the walls.

In the prepositional phrase "on the wall", "on" as preposition and "the wall" acting as object preposition, is prepositional phrase function as adverb. This preposition modifies "hung", which is an adjective. This the reason why prepositional phrase acting as adverb because the prepositional phrase modifies an adjective

Data no 12:

Sitting on a folding seat on a Line 7 train, she thought about how she would surprise her children.

One of prepositional phrase in the sentence above is "on a folding seat", "on" as preposition and "a folding seat" as object of preposition. The prepositional phrase connected with the noun is "sitting". As According Frank's theory, in position of prepositional phrase in adjectival function, prepositional phrases follow the nouns they modify. The prepositional phrase found in the sentence above is follow the noun "Sitting", this prepositional phrase modifies noun functions as an adjective phrase.

Data no 13:

Sitting on a folding seat on a Line 7 train, she thought about how she would surprise her children.

Another prepositional phrase in the sentence above is "on a line 7 train", "on" as preposition and "a line 7 train" as object of preposition. The prepositional phrase 
connected with the noun is "sitting". As According Frank's theory, in position of prepositional phrase in adjectival function, prepositional phrases follow the nouns they modify. The prepositional phrase found in the sentence above is follow the noun "Sitting", this prepositional phrase modifies noun functions as an adjective phrase.

Data no 14:

They fold the children's clothes, change the sheets on the beds.

The prepositional phrase in the sentence above is "on the beds" this prepositional phrase located after the word that modify, "the beds" as the object of preposition related to the noun "sheets". This prepositional phrase functions as an adjective because modifies a noun.

Data no 15:

Myriam and Paul sit on the edge of their bed.

First prepositional phrase in the sentence above is "on the edge". "on" as preposition and "the edge" as object of preposition. The prepositional phrase connected with the verb is "sit", this prepositional phrase modifies verb functions as an adjective phrase.

Data no 16:

Myriam and Paul sit on the edge of their bed.

The last prepositional phrase in the sentence above is "of their bed". Preposition "of" and "their bed" as a n object preposition. The prepositional phrase connected with the verb is "sit", this prepositional phrase modifies verb functions as an adjective phrase.

Data no 17:

She seemed happy to welcome a customer and equally embarrassed by the contempt she had shown

The preposition "by" and "the contempt" as an object preposition in the prepositional phrase "by the contempt", is prepositional phrase function as adverb. This preposition modifies "embarassed", which is an adjective. This the reason why prepositional phrase acting as adverb because the prepositional phrase modifies an adjective.

Data no 18:

She puts her finger in the shower and bites it to stop the bleeding.

Prepositional phrase in the sentence above is "in the shower", "in" as preposition and "the shower" as object of preposition. The prepositional phrase connected with the noun is "finger". As According Frank's theory, in position of prepositional phrase in adjectival function, prepositional phrases follow the nouns they modify. The prepositional phrase found in the sentence above is follow the noun "finger", this prepositional phrase modifies noun functions as an adjective phrase. 
Data no 19:

She picks up the ballet pumps that she left on the floor, a pair she bought more than ten years ago but which she's taken such good care of that they still look new.

In the sentence above the prepositional phrase is "up the ballet pumps". "up" as preposition and it is followed by "the ballet pumps", which is the object of preposition in the sentence. The prepositional phrase "up the ballet pumps" modify the word "picks", and it is a verb. The position of prepositional phrase to the children is adverbial position.

Data no 20:

She sits down and starts cleaning one, soaking a piece of cotton wool in a pot of make-up remover.

In the sentence above there are two prepositional phrases. The first prepositional phrase is "of cotton wool", "of" as preposition and "cotton wool" as an object preposition, is a prepositional phrase function as adverb. This preposition modifies "piece", which is a noun. This the reason why prepositional phrase acting as adjective because the prepositional phrase modifies a noun

\section{Conclusion}

Based on the findings above, it can be concluded that position of prepositional phrases that usage in the novel The Perfect Nany written by Leila Slimani is mostly a prepositional phrase adverbial function. This is because the adverbial function can modify verbs, adverbs and adjectives that are found in the novel. Meanwhile the adjectival function position of the prepositional phrase that only changes the noun head is not as much as the adverbial function.

\section{References}

Alexander, J. C. (1988). Action and Its Environments: Toward a New Synthesis. Columbia: Columbia University Press.

Frank, M. (1972). Modern English. New Jersey: Prentice Hall Inc.

George E. Wishon, J. M. (1980). Let's Write English. USA: Atlantis Publishers.

Hamataher, S. (2012). Analysis Of Error Of use Prepositiona And factor Caused In Writing.

Morley, G. D. (2000). Syntax in Functional Grammar: An Introduction to Lexicogrammar in Systemic Linguistic. New York: A\&C Black. 